theme 1

theory

author(s) strand 3

aesthetics beyond style

\title{
Aesthetic Appeal \\ Meaning Formulation and Cultural Framing in Design
}

This paper is a theoretical contribution to an aesthetics of design beyond style. The paper will present an interpretive framework for investigating and questioning the formation and articulation of aesthetic meaning in design. In the context of the paper, aesthetic meaning can be seen to evolve on three levels: 1) On a sensual-phenomenological level, the focus is on sensual appeal, i.e. how the design object by its sensual and tactile effects and its outer shape creates an appeal to human experience. This is not a matter of style but of the object relating to and framing the conditions of experience, e.g. in appeal to emotions or pleasure. 2) On a conceptual-hermeneutical level, the staging of meaning by design objects is in question. This regards, on the one hand, the appeal to understanding by the human subject and, on the other hand, the ability of the object to reflect its own character as a site of meaning formulation. 3) On a contextual-discursive level, the focus is on the contextual factors of the aesthetics of the design, that is, on the cultural element of aestheticization where design in different ways and by different means is reflected, regarded and positioned as 'aesthetic'. The paper will conclude by pointing at the impact of the cultural framing of design and the procedures by which design objects are not only regarded as aesthetic by their inherent qualities but are also attributed meaning and value as aesthetic by external factors, e.g. in visual mediation. Thus, the question of aesthetics in design may be answered by both addressing the internal meaning formulation of the aesthetic appeal and the external cultural and discursive framing of design that influences how design is perceived as 'aesthetic'.

keywords design, aesthetics, aestheticization, meaning, cultural framing

\section{Introduction}

Often, the discussion of aesthetics in design is based on a series of paradoxes: The concept of aesthetics is integrated in the common discourse on design and often set in relation to design, while at the same time, what is meant by the concept is rarely clarified; furthermore, there is a strong philosophical tradition for the discussion of aesthetics, especially in relation to art, while this is rarely related to design.

Although aesthetics in design has been a neglected area of research, attempts have been made to conceptualize the specific field of a specialized 'design aesthetics'. Roughly speaking, these attempts take their starting point in either design, often in issues of design practice, or the philosophical understanding of aesthetics. In relation to design, a dominant concern has been to understand the aesthetic qualities of the non-functional, emotionally appealing factors in design and how they affect the process of designing. In relation to the philosophical interest in aesthetics, the field has expanded from an interest in art and taste toward an interest in design. This is reflected by the recent book by Forsey 
(2013), which aims to formulate a specific philosophical aesthetics for design and relating it to the field of 'Everyday Aesthetics'. Aesthetics is no longer the exclusive domain of art but is also as a concept applied to our immediate, sensuous experience of the world (see e.g. Saito 2010 \& Leddy 2012).

In this paper, I will regard aesthetic meaning to evolve in a dynamic relationship of a subject with an intention to see and perceive something as aesthetic and an object with certain aesthetically coded features (e.g. Genette 1999). With this outset, the paper will present an interpretive framework for investigating the formation and articulation of aesthetic meaning in design. Aesthetics will be approached as an entry into the discussion of the appeal to experience and understanding by design objects, that is, how design objects mange to frame and appeal to modes of experience, engage processes of understanding and affect its context. I will point to three levels of aesthetics and aesthetic theory: a sensual-phenomenological level, a conceptual-hermeneutical level, and a discursive-contextual level (cf. Folkmann 2013).

Further, by looking at design as part of a larger system of "design culture" where conditions of production, motifs and ideologies of designers and patterns of consumption play central roles (Julier 2008), we can look at aesthetic meaning and value as something that is attributed to design objects, e.g. by devices of media and mediation. By this, a complex logic of aesthetizication is at play, when more and more objects are drawn into the field of aesthetic meaning.

\section{The Sensual-Phenomenological Dimension of Aesthetics}

In recent years there has been a tendency to loosen the connection between art and aesthetic theory and to revisit Baumgarten's original idea of applying aesthetics to sensual matter in the work Aesthetica (1750-58; in Old Greek, aisthetá means "that which can be sensed"). This has been developed in works by the philosophers Martin Seel (2000, 2007), Gernot Böhme (2001, 2013), and, drawing on John Dewey's Pragmatist aesthetics (2005), Richard Shusterman (2000). These inquiries deal with aspects of sensual appeal and the question of appearance, that is, on the one hand, how people respond to certain kinds and structures of appearance, and, on the other hand, how these are constituted in order to evoke response.

The term "phenomenological" can be used, as this view on aesthetics deals with the experience of things and, more importantly, with the ways in which objects influence and condition experience. Key concepts here are "pure presence", a term that was introduced by Seel, and which designates special attention to and attraction from appearance, and "ambience", introduced by Böhme as a term for the influence from the surroundings on perception. Even if these concepts are only briefly related to design by the authors, they are nevertheless powerful means of examining how design objects specifically have a sensual impact, operate as appearance, and contribute to the creation of ambience.

This aspect of aesthetics mainly concerns the sensual communication of the form and material-tactile dimension of the artefact, how it is staged as appearance and a presence to be noticed, appreciated and apprehended as pleasurable or emotionally appealing or to slip more anonymously into the mainstream of products. Thus, this is a level of sensuous meaning in design regarding its degree of creating an appeal to a human subject who is prepared to receive the aesthetic intention of the object. With regard to industrial design, this aspect of aesthetics deals with the sensual meaning of the artifact: the look, the feel 
of the texture, the application of materials, the execution of the detailing in the assembly and seamless fittings, as well as the sensual appeal of the overall physical presence and the immediate emotional stimulation of the user. Thus, addressing the sensualphenomenological dimension of aesthetics means to acknowledge the material element of all kinds of artifacts.

\section{The Conceptual-Hermeneutical Dimension of Aesthetics}

While the emphasis on sensual issues can be traced back to Baumgarten, the conceptualhermeneutical dimension of aesthetics has mainly been developed in relation to art. The key concern here has not been to celebrate artistic creation but rather to analyze art as a medium for the construction of meaning and new patterns of understanding. This line of investigation was initiated in Kant's Kritik der Urtheilskraft (1790), where aesthetics (albeit in relation to our experience of nature) was conceived as a basic aspect of epistemology: Kant's idea was to employ aesthetics in bridging sensual appearance and conceptually formulated meaning. Following this line of reflection, much of so-called philosophical aesthetics has been guided mainly by philosophical concerns about epistemology and the construction of meaning and often less by an interest in the specific communicative abilities and conceptual strategies of the medium in question.

Design research has given little consideration to this tradition of aesthetics, perhaps because of its focus on works on art and the often abstract philosophical vocabulary. The reason for integrating it into the present discussion is its focus on the enabling of meaning: the construction, articulation, conveyance and understanding of meaning. Hence, when dealing with the enabling of meaning, hermeneutics gains in importance with regard to the staging of processes of understanding (on behalf of the aesthetic medium) and with regard to their operation (in the perceiver).

A crucial aspect of this line of aesthetic theory has been an immense interest in the extraand trans-communicative effects beyond normal communicative abilities. The notion of an impossible communication that is only made possible in the closed space of the work of art has, for example, been the driving factor behind Adorno's Ästhetische Theorie (1970) and the line of aesthetic inquiry that it inspired (e.g. Bubner 1989; Menke 1991; Seel 2000). In this context, the questions to be asked of design objects are, on the one hand, how and by what means the aesthetic medium enables and constructs meaning, and, on the other hand, what is the nature of this meaning, i.e. whether it transcends any limitations, and what its implications are. Further, it can be asked how the design reflects its relation to its meaning content: Whether and how it is self-reflective with regard to its meaning (e.g. how does Philippe Starck's (in?)famous Juicy Salif reflect the idea of a lemon squeezer?).

Thus, we may ask a number of questions regarding the relationship of design to its content of meaning. It is not enough to ask what the meaning of a specific design is on a conceptual level (its 'idea' or meaning content); we must also ask how it performs or reflects this meaning in and through its physical form and how it relates to the kind of selfreflective aesthetic function where it displays a surplus of meaning. How can a surplus of meaning be invested in design, and how can it be reflected in an actual design?

\section{The Contextual-Discursive Dimension of Aesthetics}

While the two previous dimensions of aesthetics deal with aspects of meaning aspects 
of the given design object, the contextual-discursive dimension focuses on the wider implications of the circulation of objects on a cultural, social, and political level. According to the cultural theorist Jacques Rancière, who has influenced this trend in aesthetic theory, aesthetics can be investigated as a political power issue in relation to the distribution of sensual material and the ability to determine "what presents itself to sensory experience": Thus, aesthetics can be seen as "a delimitation of spaces and times, of the visible and the invisible, of speech and noise, that simultaneously determines the place and the stakes of politics as a form of experience" (Rancière 2004 : 13). Rancière seeks to discuss possibilities that are determined by aesthetic media; these not only behave as transmitters of new possible meaning but also produce possibilities by defining and conditioning domains of the sensual experience.

This approach to a delineation of what can be experienced and sensed relates to the cultural discussion of aestheticization and Everyday Aesthetics. Aestheticization can be seen as a ubiquitous process of distributing sensual meaning (cf. Oldemeyer 2008) as we are surrounded by things that strive for sensual appeal and by an attribution of symbolic meaning can play a social and cultural role in people's construction of their identities. On this level, the artifacts form part of an exchange of value and symbolic meaning between people. The question of how people develop an attachment to objects is especially related to studies in consumption, to sociology, and to anthropologically informed material culture studies, but it should be acknowledged as part of the various aesthetic effects of design objects.

To enter a discussion of aestheticization may be to examine how the interface that we apply when we meet the world is changing as a result of strategies of making objects and surfaces more sensually appealing, applying aesthetic coding, and asking how this process affects experience. In this sense, aestheticization is not about an artificial and superficial creation of meaning but deals with the staging and distributing meaning in a way that changes the conditions of experience.

\section{Conclusion: The Cultural Framing of Design Aesthetics}

Through the prism of aesthetic theory, various levels of meaning formation in design come into sight. Further, the question of aesthetics in design is also a question of how a domain of 'aesthetic' meaning is strategically related to the design object by factors external of the objects. This opens for a discussion of the cultural factors surrounding and circumscribing design. Thus, the question is not only how design is aesthetic (as suggested in the three dimensions above) but also how it is being regarded and positioned as aesthetic, that is, created as 'aesthetic'.

Here, we enter a vast field of cultural theory and approaches to cultural analysis of design which aims to analytically describe design in its relation to and dialogue with its formative contexts (e.g. Hebdige 1988; du Gay et al. 1997; Julier 2008). Thus, we (also) have to look for the cultural construction of design as 'aesthetic', that is, of design as something that is attributed and imbued with a kind of meaning that can be labeled 'aesthetic'. Designers, manufacturers, retailers, design magazines, blogs, etc., all the actors in the cultural circuit of design, may employ the term 'aesthetic' in relation to the design objects in question and install a notion that the object in fact may be regarded as aesthetic. Design object may have an inherent aesthetic potential that in meaning processes surrounding the design can be promoted or even exploited. 
By this, the game about aesthetic meaning is a dual one. The object may in itself entail a potential for aesthetic meaning. This can then be actualized in and through the contexts the object is a part of and engages with.

\section{References}

Adorno, T. W. (1970) Ästhetische Theorie, Frankfurt am Main: Suhrkamp.

Böhme, G. (2001) Aisthetik. Vorlesungen über Ästhetik als allgemeine

Wahrnehmungslehre, Munich: Wilhelm Fink Verlag.

Böhme, G. (2013) Atmosphäre. Essays zur neuen Ästhetik, Frankfurt am Main: Suhrkamp.

Bubner, R. (1989) Ästhetische Erfahrung, Frankfurt am Main: Suhrkamp.

Dewey, J. (2005) Art as Experience, New York: Penguin.

du Gay, Paul et al. (1997) Doing Cultural Studies. The Story of the Sony Walkman, London: Sage.

Folkmann, M. N. (2013) The Aesthetics of Imagination in Design. Cambridge, MA: MIT

Press.

Forsey, J. (2013) The Aesthetics of Design, Oxford: Oxford University Press.

Genette, G. (1999) The Aesthetic Relation. Ithaca, NY: Cornell University Press.

Hebdige, D. (1994) 'Object as Image: the Italian Scooter Cycle', in Hiding in the Light,

London: Routledge.

Julier, G. (2008) The Culture of Design, London: Sage.

Julier, G. (2013) http://designculturekolding.org/2013/10/01/design-culture-and-

discourse/ (accessed 2013-01-22)

Leddy, T. (2012) The Extraordinary in the Ordinary. The Aesthetics of Everyday Life,

Peterborough: Broadview Press.

Menke, C. (1991) Die Souveränität der Kunst, Frankfurt am Main: Suhrkamp.

Oldemeyer, E. (2008) Alltagsästhetisierung: Vom Wandel ästhetischer Erfahrung,

Würzburg: Königshausen \& Neumann.

Rancière, J. (2004) The Politics of Aesthetics, London: Continuum.

Saito, Y. (2010) Everyday Aesthetics, Oxford: Oxford University Press.

Seel, M. (2000) Ästhetik des Erscheinens, Munich: Hanser.

Seel, M. (2007) Die Macht der Erscheinung, Frankfurt am Main: Suhrkamp.

Shusterman, R. (2000) Pragmatist Aesthetics: Living Beauty, Rethinking Art, Lanham, MD:

Rowman \& Littlefield 
